\section{SCIDOC Publishers}

\title{
Magnitude and Predictors of Premarital Sexual Practice among Unmarried Undergraduate Students, at Arba Minch University, Ethiopia, 2015
}

Research Article

Sorato $\mathrm{MM}^{*}$, Belijo ZN

Clinical Pharmacist, Arba Minch College of Health Sciences, Ethiopia.

\section{Abstract}

Background: Pre-marital sexual practice increases the risk of sexually transmitted infections (STIs) including HIV/AIDS and unwanted pregnancy. It may also affect their school performance and completion rate. In spite of this fact, magnitude of pre-marital sexual practice is increasing from time to time.

Objective: To determine the magnitude and predictors of premarital sexual practice among unmarried undergraduate Arba Minch University, students, 2015.

Methods: Institution based cross sectional study design was used. A total of 575 students were selected by multi-stage sampling technique from six Colleges. Data was collected by using pre-tested self-administered questionnaire. Data entry was done by using epi info version 7 and exported to SPSS version 20 for analysis. Descriptive statistics, binary and multivariable logistic regression analyses used to identify factors associated with pre-marital sexual practice.

Results: A total of 575 students were participated in our study. Four hundred thirty two (75.2\%) and $143(24.8 \%)$ were Males and Females respectively. The majority of study participants $382(66.4 \%)$ were in the age group of 21 to 25 years with mean age of $21.25 \pm 1.732$ years. Three hundred forty one (59.3\%) were orthodox by religion; $196(34.1 \%)$ were Amhara by ethnicity. Predictors of pre-marital sexual practice include; Male sex $[\mathrm{AOR}=1.329,95 \% \mathrm{CI}=1.129,3.880]$, Academic year $[\mathrm{AOR}$ $=0.540,95 \% \mathrm{CI}=0.187,1.556]$, Pocket money $[\mathrm{AOR}=0.096,95 \% \mathrm{CI}=0.010,0.888]$, Exposure to Reproductive health information $[\mathrm{AOR}=0.995,95 \% \mathrm{CI}=0.988,1.012]$, Family discussion about sexual issues $[\mathrm{AOR}=0.818,95 \% \mathrm{CI}=0.852$, 1.218], Exposure to pornographic films [AOR $=3.854,95 \% \mathrm{CI}=0.945,11.055]$ and others.

Conclusion: More than one third of participants had premarital sexual practice and it is higher in males than females. Factors affecting pre-marital sexual practice include; Male sex, Pocket money, Exposure to Reproductive health information, Exposure to pornographic films, Alcohol use, Chat chewing and attending religious services. Appropriate interventions should be done by responsible bodies to reduce premarital sexual practice.

Keywords: Premarital Sexual Practice; Sexuality; Unmarried; Undergraduate; Arba Minch; Ethiopia.

Acronyms: AIDS: Acquired Immunodeficiency Syndrome; AMU: Arba Minch University; BCC: Behavioral Change and Communication; DHS: Demographic Health Survey; EPHA: Ethiopian Public Health Association; HIV: Human Immune Deficiency Virus; IEC: Information Education and Communication; MOH: Ministry of Health; SD: Standard Deviation; SES: Socio Economic Status; SNNPR: Southern Nations Nationalities and Peoples Region; SPSS: Statistical Package for Social Science; SRS: Simple Random Sampling; STD: Sexually Transmitted Diseases; WHO: World Health Organization.

\section{Introduction}

Pre-marital sex is any sexual activities (penetrative vaginal or anal sexual intercourse) with an opposite sex partners or a same sex before he/she has started a marriage life [1]. Most age groups that started pre-marital sex are adolescent and young people. There are
1.2 billion adolescents and 1.7 billion young people in the world today of which $85 \%$ of them live in developing countries. Adolescent age is a time to experiment with sexual practice [2]. Premarital sex and unprotected sexual practices are major threat to the health and survival of millions of adolescents each year one in 20 adolescents contracts on STIs including HIV/AIDS [3].

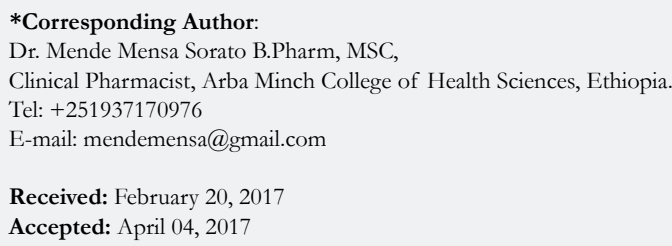

Citation: Sorato MM, Belijo ZN (2017) Magnitude and Predictors of Premarital Sexual Practice among Unmarried Undergraduate Students, at Arba Minch University, Ethiopia, 2015. Int J Reprod Fertil Sex Health. 4(2), 95-104. doi: http://dx.doi.org/10.19070/2377-1887-1700017

Copyright: Sorato $\mathbf{M M}^{\odot}$ 2017. This is an open-access article distributed under the terms of the Creative Commons Attribution License, which permits unrestricted use, distribution and reproduction in any medium, provided the original author and source are credited. 
According to Ethiopian Demographic and Health Survey (EDHS) 2011; among women age 25-49 years, 29\% first had sexual intercourse before age $15.62 \%$ before age 18 , and by age 25 the majority of Ethiopian women (88\%) had had sexual intercourse. The median age at first sexual intercourse has increased over the past two decades, from 15.6 years for women currently age $45-49$ to 18.8 years for women currently age 20-24 [4].

Study done in Gamo Gofa Zone, showed that majority of young adults who easily fall prey to excitement coupled with the liberal nature of campus life that predisposes them to high risk sexual behavior. Physiologically, the changes in reproductive organs that occur in the life of adolescents often serve as a motivating force in their quest to experiment with sex [5]. Pre-marital unsafe sex is risk factor to STDs, HIV/AIDS, unwanted pregnancy and subsequent dropout from school, illegal abortion and its complication, social and psychological transmit. Different studies identified inconsistent factors of pre-marital sexual practice like pear pressure, age of students, religiosity, having pocket money, watching pornographic video, family residence and parental educational status, gender, educational level, watching pornography, khat and alcohol utilization [6-9]. Studies conducted so far on pre-marital sexual practices and predictors to it in Ethiopia were few. Selection of AMU for this study was based on high number of students and location of the university is within the town where daily visited by large number of tourist. This study showed current magnitude of premarital sexual practices and predictors to it in AMU, which might help the concerned bodies to take actions based on the findings and the study might provide base line information for further studies that may be conducted in similar issues.

\section{Concept of Premarital Sex and Associated Factors Review}

Sexuality is a concept encompassing the whole person, including the physical body, inherited characteristics, the feeling and attitudes, the styles, the behaving, the decisions, beliefs, and values around sexual issues or sexual life, the relationships, the social and spiritual aspects of being a female or male. Improved socioeconomic standards and nutrition have decreased the age of onset of sexual maturation. Since adolescence is age of choice and they are less mature mentally/emotionally, they are often ill prepared to make the serious decisions they face [10-12].

According to the 2005 Ethiopian behavioral surveillance survey, the prevalence of premarital sexual practices among in-school youths in Amhara Region was 4.5\% [13]. Study done in northern Ethiopia revealed that more than one fifth $(21.1 \%)$ of respondents were involved in premarital sexual practice [14]; Study conducted in Jimma University preparatory showed that prevalence of premarital sexual practice was $28.2 \%$ [15]; study conducted in Jigjiga University, showed that majority $122(67.67 \%)$ of the respondents reported that they have had premarital sexual practice [16]. Other studies conducted among adolescents in Ethiopia revealed that the prevalence of premarital sex among school youth in Oromia $(31.3 \%)$ and nationally (19\%) [17] and a study conducted among Addis Ababa University Undergraduate Students revealed $39 \%$ of the participants had premarital sexual practice [18].

The contributing factors for high risky sexual practices among college students were technological transitions, which make it easier to distribute sexual information from more liberal to more conservative societies; peer pressure; unlicensed erotic films; drugs and alcohol abuse [19, 20]. Study done in northern Ethiopia showed that adolescents who watch sex/pornographic movies were more likely to engage in premarital sexual practices [14]. Another study done in Ethiopia showed that watching pornographic materials at age less than 18 years old was found to be associated with sexual initiation [23]. Study done in Asian country showed that, pornography viewing was found to be significant factor for premarital sex among boys [24].

Study conducted among adolescents in Eastern Ethiopia showed that $24 \%$ of in-school in started sex at an average age of 15.5 years [21]. Similar study conducted In Indonesia, showed that $32 \%$ of students experienced their first sexual intercourse at the age of $13-14$ years and $68 \%$ of them at 15 years [22]. A study done among youths in Harar revealed that, $48.1 \%$ of males and $37.8 \%$ of females, had their first sexual encounter at 15-17 years of age. The mean age at first sexual exposure among unmarried youths was 17.2 years (16.9 and 18 years for males and females respectively) [25].

Studies showed that adolescents who have more pocket money tend to practice pre-marital sexual practice [26] and insufficient knowledge of reproductive health and family planning, engage in premarital sex and the small proportion them use contraceptive than those with good knowledge about it [27]. Study conducted in china, showed that Prevalence of Premarital sexual practice was $17.6 \%$ among males and $8.6 \%$ among females [28]. In a study conducted in Philippines showed that Males were significantly more likely than females to have ever had sexual intercourse $30 \%$ vs. $7 \%, \mathrm{p}=001)[29]$.

Study conducted among Mexican adolescents showed that the extent of parent-adolescent communication regarding, reproductive health issues combined with strong parental control was significantly associated with adolescent sexual behavior [31]; Similar study conducted in Ethiopia showed that the desire to maintain relationship with friends of elders, living with single parents or poor religious activity are important in term of influencing adolescents sexuality [15]. Study conducted in Jigiga University, showed that $37(25.20 \%)$ reported that they or their sexual partners used alcohol and $12(8.20 \%)$ them had sex while they were drunk. This study also revealed the about 16 (10.90\%)chewed chat during their last sexual encounter [16].

\section{Objectives of the Study}

\section{General Objective}

To determine the magnitude and predictors of premarital sexual practice among AMU students, Arba Minch University, Southern Ethiopia, May 2015.

\section{Specific Objectives}

To determine the magnitude of premarital sexual practice among AMU students.

To identify predictors of premarital sexual practice among AMU students. 


\section{Methodology}

\section{Study Area and Period}

Study was conducted in Arba Minch University from March $1^{\text {st }}$ to March 20 and analysis was done March 21 ${ }^{\text {st }}$ to May 20, 2015. Arba Minch University is one of the higher learning institutions in Ethiopia established in 1862/63. The university is located in Arba Minch town, which is located in GamoGofa Zone, SNNPR; South of Ethiopia located $505 \mathrm{KMs}$ from Addis Ababa. There are one teaching and one district hospitals rendered to provide both preventive and curative health services in the zone. The university has five campuses namely main campus, chamo campus, nechsar campus, kulfo campus and abaya campus. Currently, there are over 2080 academic staff, 3147 administrative staff, and 17,627 regular and 3882 postgraduate and evening students enrolled in 50 undergraduate and 40 postgraduate programs.

\section{Study Design}

Institution-based cross-sectional study was conducted in order to measure the magnitude and associated factors with Pre Material sexual practice.

\section{Source Population}

All regular undergraduate AMU students enrolled in the current academic year and the study populations were all regular undergraduate AMU students in the selected campuses.

\section{Inclusion Criteria and Exclusion Criteria}

Inclusion Criteria: Regular unmarried undergraduate students in the University who fulfilled inclusion criteria.

\section{Exclusion Criteria:}

Married Students.

Students who were unable to communicate due to severe illness.

\section{Variables of the Study}

Dependent Variable: Premarital sexual practice.

\section{Independent Variables:}

Socio-economic factors: Age, Sex, religion, ethnicity, residence, educational status, occupational status, Pocket money, Pornographic/Erotic Films, Substance abuse, Number of Sexual Partners, condom use,

Peer and family factors: Exposure to reproductive health information, source of information, Sexual Issues discussion with family, attending religious services.

\section{Sample Size Determination}

The sample size was calculated based on single population proportion by using the following assumptions. The assumption was by taking $\mathrm{p}$-value from a research done among Addis Ababa University Undergraduate Students, where prevalence of premarital sexual practice was, $(\mathrm{P}=34.7 \%)[18]$, Level of confidence $=95 \%$
$\left(\mathrm{Z}_{\alpha / 2}=1.96\right)$ and $\mathrm{D}=0.05$ (marginal error) and adding of $10 \%$ Non-respondents and 1.5 for design effect or the multistage stage sampling technique used.

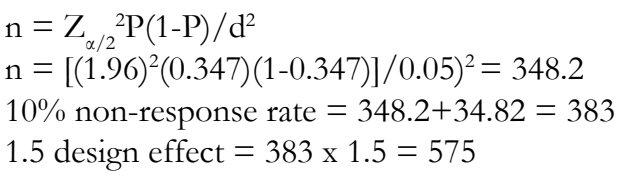

Where

$\mathrm{n}=$ required sample size.

$\mathrm{p}=$ estimate of prevalence rate of premarital sexual practice.

$\mathrm{Z}_{\alpha / 2}{ }^{2}=$ standard normal variable at $95 \%$ confidence level $(95 \%=$ 1.96 from table).

$\mathrm{d}=$ margin of sample error tolerated $=0.05$.

The sample size from each collage was calculated as follows:

Sample from each collage $=$

(Number of students in each collage $\mathrm{x}$ sample size(n))/(total number of source of population.)

The final sample size sample size was 575 students.

\section{Sampling Technique}

All campuses in Arba Minch University were included in the sampling technique and departments included in the study were selected by lottery method and finally proportional allocation was made based on the number of students from respective academic year from each department were considered to select individual study units and 575 students were randomly selected from each department during the study period.

\section{Data Collection Procedure}

The quantitative data was collected using questionnaire in the selfadministered way. The questionnaire was adapted from other related studies. The questionnaire was originally prepared in English language and translated into Amharic.

\section{Data Quality Control}

Data collectors and supervisor were trained on objectives of the study, confidentiality of information, contents of the questionnaire and data quality management by the principal investigators. The questionnaire was pretested in $28(5 \%)$ of actual sample size in AMU Main campus students for clarity and consistency of the questions. Appropriate amendments were made after the pretest. During data collection days, the principal investigators and supervisors checked data for completeness and clarity.

\section{Data Analysis}

Cross-checking and data cleaning was done for accuracy and consistencies carried out by running frequencies of each variable by principal investigators. The data was checked for completeness, consistencies, cleaned then coded and entered in to epi info version 7 and exported into SPSS for windows version 20 for analysis. Descriptive statistics were computed to determine the magnitude of premarital sexual practice. Bivariate analysis was done to evalu- 
ate associations of each independent variable with the outcome variables. Variables which show significant association with the outcome variables in the bivariate analysis were entered into multiple logistic regression models to control for confounding and identifying independent predictors of premarital sexual practices.

\section{Operational Definition}

Age of sexual debut: The age at which the first sexual commencement occurred.

Casual sex: Sexual intercourse with a non-regular partner.

Coituerche: the age at first sexual intercourse.

Early sexual initiation: is having sexual intercourse before the age of 18 years.

Life time sexual partner (LTSP): the number of sexual partners he/she had since his/her initiation of vaginal intercourse.

Peer influence: Influence resulted to do something by members of a person's own age group, occupation, or social group.

Pornographic/Erotic Films: Movies/magazines and other entertainment that show sexual acts explicitly and intended to cause sexual arousal.

Pre-marital sex (PMS): Any sexual intercourse practiced before marriage.

Premarital sex: A student who ever had penetrative vaginal or anal sexual intercourse before marriage.

Sexual active: A student who had penetrative sexual intercourse at least once prior to the study.

Substance use: Excessive consumption or misuse of substance; excessive consumption misuse of a substance for sake of its nontherapeutic effect on the mind or body.

Unsafe sex: Sex practiced with multiple sexual partners and/or without using condom.

\section{Ethical Consideration}

The proposal was submitted to the Research Ethics Committee (REC) of Addis continental institute of Public Health. Ethical clearance was obtained from Addis continental institute of Public Health. Permission letter was obtained from Arba Minch University. Verbal consent was taken from each participant after the purpose of the study was explained.

\section{Dissemination of Results}

The result of the study was presented to Addis continental institute of Public Health; Arba Minch University College of Medicine and Health sciences; Department of public Health and concerned bodies who work on adult sexuality and sexual health. Attempt will be made to publish in peer reviewed national or international scientific journal.

\section{Results}

\section{Socio Demographic Characteristics of Respondents}

A total of 575 students were participated in our study. Four hundred thirty two $(75.2 \%)$ and $143(24.8 \%)$ were Males and Females respectively. The majority of study participants $382(66.4 \%)$ were in the age group of 21 to 25 years with mean age of $21.25 \pm$ 1.732 years. Three hundred forty one $(59.3 \%)$ were orthodox by religion followed by protestant and majority of the respondents
196 (34.1\%) were Amhara by ethnicity. Most of respondents were from urban area; $39.3 \%$ of mothers and $25.7 \%$ of fathers were illiterate. With regard to occupational status 306 (53.2\%) of mothers were house wives and $234(40.7 \%)$ of fathers were farmers (Table 1).

\section{Premarital Sexual Practice Related Factors}

Two hundred fortyeight (43.1\%) of respondents had had premarital sex and majority of them had first sex in age of 16-20 years with mean age of $18.23 \pm 1.955$ years. Most of respondents $342(59.5 \%)$ were received pocket money from family below 400 Ethiopian birr per month with mean monthly pocket money of $448.02 \pm 362.82$ Ethiopian birr. Above one half of participants $329(57.2 \%)$ had exposure to erotic films or pornography (Table $2)$.

With regard to academic year $217(37.7 \%)$ were from $3^{\text {td }}$ year, 188 $(32.7 \%)$ were from $2^{\text {nd }}$ year and $112(19.5 \%)$ were $1^{\text {st }}$ year students (Figure 1).

With regard to reason of first sex the most common were fall in love $150(42.3 \%)$ followed by peer pressure 49 (19.8\%). Only 96 $(38.7 \%)$ of respondents had used condom every time during sex. Reasons for not Using Condoms more than one third 33 (42.9\%) of respondents reported that "I trust my partner" followed by it is not comfortable $13(16.9 \%)$ (Figure $2 \& 3$ ).

\section{Drug use Related Factors}

One hundred ninety three $(33.6 \%)$ of participants reported that they had alcohol use experience during study period and about $129(66.8 \%)$ of these students had sexual intercourse after taking alcohol. Regarding chat use 103 (17.9\%) of participants had chat chewing experience and among chewers $74(71.18 \%)$ had sex after chewing chat. There are $26(4.5 \%)$ participants who had experience of using wed during study period and $13(50 \%)$ of participants had reported experience of sexual intercourse after using wed (Table 2).

\section{Attitude Related Factors}

Above one half 136 (54.6\%) of participants have two sexual partners, $484(84.2 \%)$ had exposure to reproductive health information. The most common source of reproductive health information as reported were radio and television 186 (38.4\%) and health institution $110(22.7 \%)$. With regard to behavior about pre-martial practice majority $418(72.7 \%)$ of participants reported that it is not right to have sexual intercourse before marriage (Table 3).

Among the reported reasons for not accepting pre-martial sexual practice were; religion does not accept is the leading one 208 $(49.8 \%)$, followed by free of consequences or unplanned pregnancy 130 (31.1\%)(Figure 4).

\section{Predictors of Pre-marital Sexual Practice}

Multivariable logistic regression analysis was done to identify factors affecting pre-marital sex among the study participants. Males were 1.3 times more likely to practice pre-marital sex as compared to females, $[\mathrm{AOR}=1.329,95 \% \mathrm{CI}=1.129,3.880]$, First year students were less likely $[\mathrm{AOR}=0.540,95 \% \mathrm{CI}=0.187,1.556]$ 
Table 1. Socio Demographic Characteristics of AMU Students, May 2015 ( $n=575)$.

\begin{tabular}{|c|c|c|}
\hline Socio Demographic Characteristics & Frequency & Percent \\
\hline $\begin{array}{c}\text { Sex }(n=575) \\
\text { Male } \\
\text { Female } \\
\end{array}$ & $\begin{array}{l}432 \\
143 \\
\end{array}$ & $\begin{array}{l}75.1 \\
24.9 \\
\end{array}$ \\
\hline $\begin{array}{l}\text { Age }(\mathbf{n}=\mathbf{5 7 5}) \\
15-20 \text { years } \\
21-25 \text { years } \\
26 \text { and above }\end{array}$ & $\begin{array}{c}188 \\
382 \\
5\end{array}$ & $\begin{array}{c}32.7 \\
66.4 \\
0.9\end{array}$ \\
\hline $\begin{array}{l}\text { Religion }(\mathrm{n}=\mathbf{5 7 5}) \\
\text { Orthodox } \\
\text { Muslim } \\
\text { Protestant } \\
\text { Catholic } \\
\text { Others }\end{array}$ & $\begin{array}{c}341 \\
80 \\
132 \\
4 \\
18\end{array}$ & $\begin{array}{c}59.3 \\
13.9 \\
23 \\
0.7 \\
3.1\end{array}$ \\
\hline $\begin{array}{c}\text { Ethnicity }(\mathbf{n}=\mathbf{5 7 5}) \\
\text { Oromo } \\
\text { Amhara } \\
\text { Wolayita } \\
\text { Gurage } \\
\text { Tigre }\end{array}$ & $\begin{array}{c}137 \\
196 \\
163 \\
56 \\
23\end{array}$ & $\begin{array}{c}23.8 \\
34.1 \\
28.3 \\
9.7 \\
4.0\end{array}$ \\
\hline $\begin{array}{c}\text { Family Residence }(\mathrm{n}=\mathbf{5 7 5}) \\
\text { Urban } \\
\text { Rural }\end{array}$ & $\begin{array}{l}366 \\
209\end{array}$ & $\begin{array}{l}63.7 \\
36.3 \\
\end{array}$ \\
\hline $\begin{array}{c}\text { Educational status of Mother }(\mathbf{n}=\mathbf{5 7 5}) \\
\text { Illiterate } \\
\text { Completed primary school } \\
\text { Completed secondary school } \\
\text { Above secondary school }\end{array}$ & $\begin{array}{c}226 \\
167 \\
80 \\
102\end{array}$ & $\begin{array}{l}39.3 \\
29.0 \\
13.9 \\
17.7\end{array}$ \\
\hline $\begin{array}{c}\text { Educational status of father }(\mathrm{n}=\mathbf{5 7 5}) \\
\text { Illiterate } \\
\text { Completed primary school } \\
\text { Completed secondary school } \\
\text { Above secondary school }\end{array}$ & $\begin{array}{c}148 \\
200 \\
84 \\
143\end{array}$ & $\begin{array}{l}25.7 \\
34.8 \\
14.6 \\
24.9\end{array}$ \\
\hline $\begin{array}{c}\text { Occupational Status of Mother }(\mathbf{n}=\mathbf{5 7 5}) \\
\text { Housewife } \\
\text { Farmer } \\
\text { Merchant } \\
\text { Gov't employee } \\
\text { Day laborer } \\
\text { Private employee } \\
\text { Others }\end{array}$ & $\begin{array}{c}306 \\
92 \\
94 \\
55 \\
4 \\
19 \\
5\end{array}$ & $\begin{array}{c}53.2 \\
16.0 \\
16.3 \\
9.6 \\
0.7 \\
3.3 \\
0.9\end{array}$ \\
\hline $\begin{array}{c}\text { Occupational status of father }(\mathbf{n}=\mathbf{5 7 5}) \\
\text { Farmer } \\
\text { Merchant } \\
\text { Gov't employee } \\
\text { Day laborer } \\
\text { Private employee } \\
\text { Others }\end{array}$ & $\begin{array}{c}234 \\
122 \\
138 \\
29 \\
43 \\
9\end{array}$ & $\begin{array}{l}40.7 \\
21.2 \\
24 \\
5.0 \\
7.5 \\
1.6\end{array}$ \\
\hline
\end{tabular}

to have pre-marital sex as compared to fifth year students, Participants who earn pocket money below 400 birr per month were less likely $[\mathrm{AOR}=0.096,95 \% \mathrm{CI}=0.010,0.888]$, Participants who had Exposure to Reproductive health information were less likely $[\mathrm{AOR}=0.995,95 \% \mathrm{CI}=0.988,1.012]$ to have pre-marital sex as compared to those who do not have exposure, Participants with family discussion about sexual issues were less likely $[\mathrm{AOR}=$ $0.818,95 \% \mathrm{CI}=0.852,1.218]$, Participants who had exposure to pornographic films were 3.854 times more likely [AOR $=3.854$, $95 \% \mathrm{CI}=0.945,11.055]$ more likely to practice pre-marital sex as compared to those who did not watch films, Participants who do not use alcohol were less likely $[\mathrm{AOR}=0.300,95 \% \mathrm{CI}=0.198$, $0.454]$ to have pre-marital sex as compared to those who use al- cohol, Participants who do not chew chat were less likely [AOR $=0.325,95 \% \mathrm{CI}=0.539,1.605]$ to have pre-marital sex as compared to those who chew chat and Participants who attend religious services were less likely $[\mathrm{AOR}=0.403,95 \% \mathrm{CI}=1.555$, 1.626] to have pre-marital sex as compared to those who do not attend religious services (Table 4).

\section{Discussion}

In our study Magnitude of pre-marital sexual practice was 248 (43.1\%). One hundred sixty (64.5\%) males and 68 (35.5\%) were females. However this finding is relatively higher than similar studies conducted in other parts of the country. Study done in 
Table 2. Distribution Pre-marital Sexual Practice Related Factors among AMU Students, May 2015.

\begin{tabular}{|c|c|c|}
\hline Pre-marital Sexual Practice Related Factors & Frequency & Percent \\
\hline \multicolumn{3}{|l|}{ Experience of sexual intercourse $(n=575)$} \\
\hline Yes & 248 & 43.1 \\
\hline No & 327 & 56.9 \\
\hline \multicolumn{3}{|l|}{ Age at first sexual intercourse $(n=248)$} \\
\hline $10-15$ years & 16 & 6.5 \\
\hline $16-20$ years & 208 & 83.9 \\
\hline above 20 years & 24 & 9.7 \\
\hline \multicolumn{3}{|l|}{ Condom utilization $(n=248)$} \\
\hline Every time & 96 & 38.7 \\
\hline Occasionally & 67 & 27.0 \\
\hline Never & 85 & 34.3 \\
\hline \multicolumn{3}{|l|}{ Monthly Pocket money $(n=575)$} \\
\hline $0-400$ birr & 342 & 59.5 \\
\hline 401-1000 birr & 219 & 38.1 \\
\hline above 1000 birr & 14 & 2.4 \\
\hline \multicolumn{3}{|l|}{ Exposure to erotic films/pornography $(\mathrm{n}=575)$} \\
\hline Yes & 329 & 57.2 \\
\hline No & 246 & 42.8 \\
\hline \multicolumn{3}{|l|}{ Alcohol use $(n=575)$} \\
\hline Yes & 193 & 33.6 \\
\hline No & 382 & 66.4 \\
\hline \multicolumn{3}{|l|}{ Sex after alcohol use $(n=193)$} \\
\hline Yes & 129 & 66.8 \\
\hline No & 65 & 31.2 \\
\hline \multicolumn{3}{|l|}{ Chat use $(n=575)$} \\
\hline Yes & 103 & 17.9 \\
\hline No & 472 & 82.1 \\
\hline \multicolumn{3}{|l|}{ Sex after chat use $(n=103)$} \\
\hline No & 29 & 28.2 \\
\hline Yes & 74 & 71.8 \\
\hline \multicolumn{3}{|l|}{ Wed use $(n=575)$} \\
\hline Yes & 26 & 4.5 \\
\hline No & 549 & 95.5 \\
\hline \multicolumn{3}{|l|}{ Sex after wed use $(n=26)$} \\
\hline No & 13 & 50.0 \\
\hline Yes & 13 & 50.0 \\
\hline
\end{tabular}

Figure 1. Distribution of Study Participants based on level of Study Year AMU Students, May 2015 (n = 575).

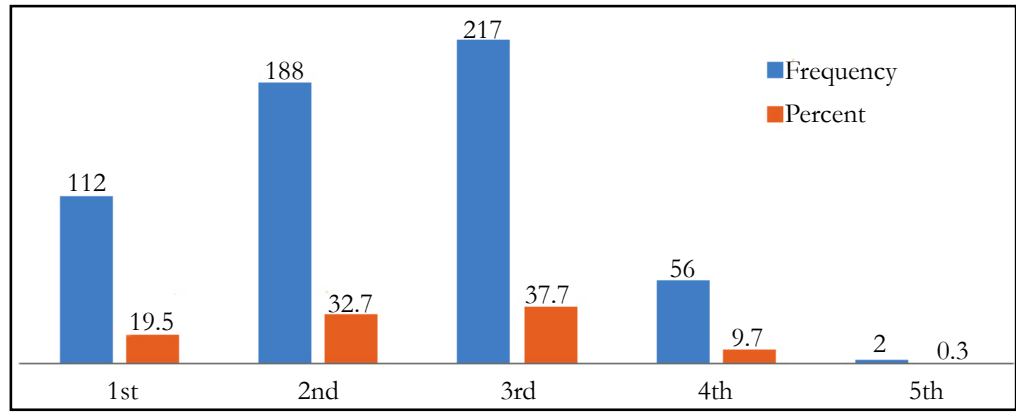

northern Ethiopia revealed that more than one fifth $(21.1 \%)$ of respondents were involved in premarital sexual practice [14] and another similar Study conducted in Jimma showed that the overall prevalence of premarital sexual practice in the study population was $28.2 \%$ [15]. These could be explained by the number of sample used, advancement in technology and that would have positively influenced participant's behavior towards premarital sexual practice and geographical location of the University where number of tourists visit per day.

This study revealed that Male participants had practiced pre-mar- ital sex more than females, $160(64.5 \%)$ of males and $88(35.5 \%)$ respectively $[\mathrm{AOR}=1.329,95 \% \mathrm{CI}=1.129,3.880]$. This is similar with study conducted in Philippines showed that Males were significantly more likely than females to have ever had sexual intercourse $(30 \%$ vs. $7 \%, \mathrm{p}=001)$. This is probably due females abstinence from premarital sexual practice due concern about the risk of pregnancy, abortion or other sexually transmitted disease [29].

This study revealed that First year students were less likely [AOR $=0.540,95 \% \mathrm{CI}=0.187,1.556]$ to have pre-marital sex as com- 
Figure 2. Reasons for First Sex of Study Participants based on Level of Study Year AMU Students, May 2015 (n = 248).

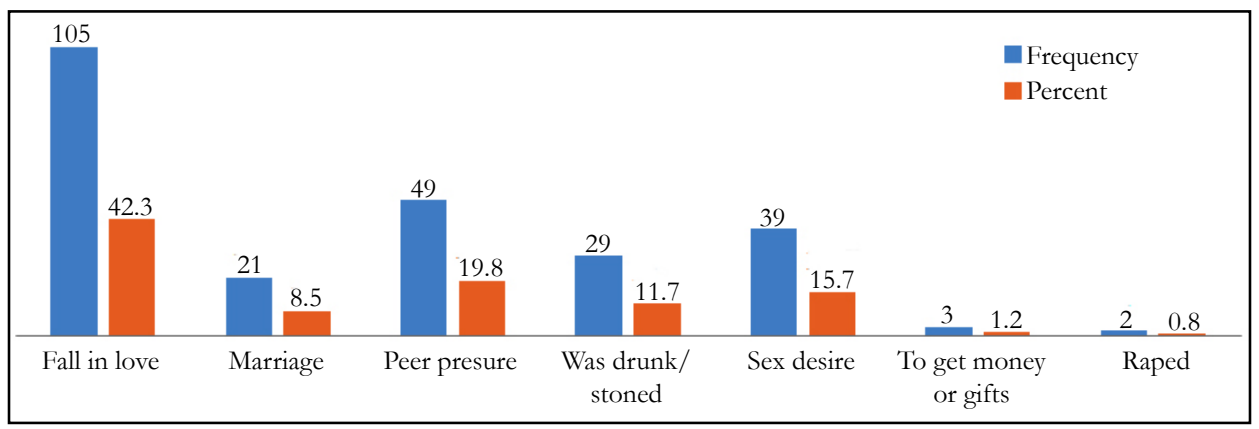

Figure 3. Reasons for not using Condom AMU Students, May 2015 (n = 85).

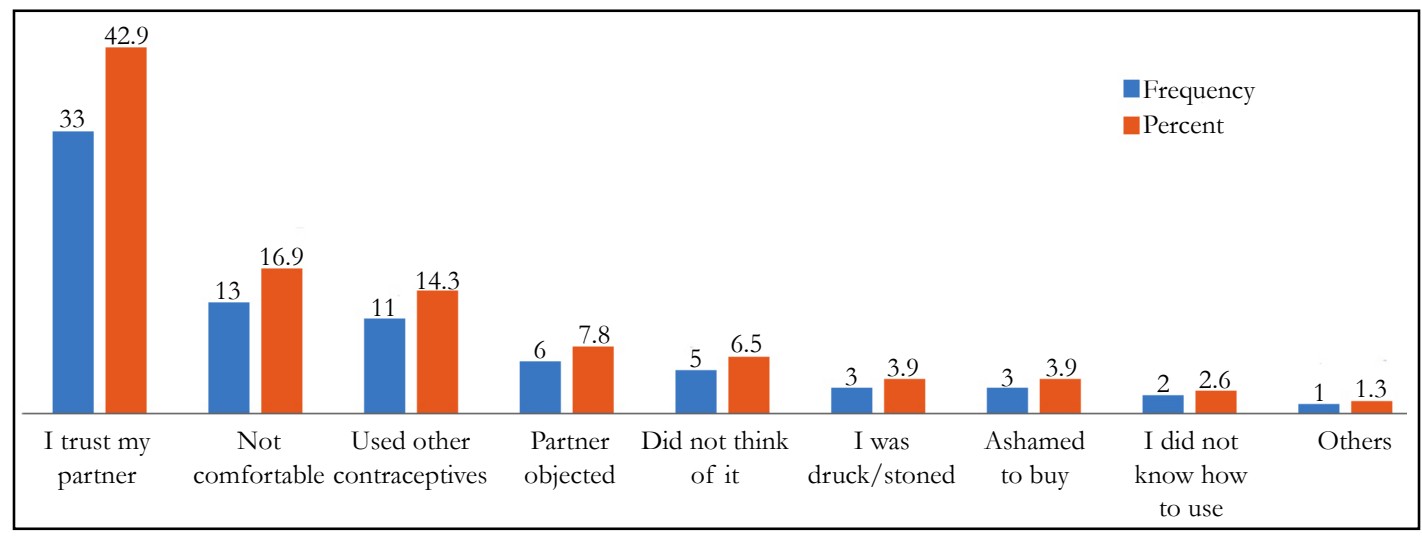

pared to fifth year students. This is consistent with study conducted in Jimma teachers training college; first year students were less likely practice pre-marital sexual intercourse than third year students, both in crude (COR $=0.51,95 \% \mathrm{CI}[0.3,0.86])$ and after controlling other factors $(\mathrm{AOR}=0.37,95 \% \mathrm{CI}[0.17,0.78])[31]$.

In this study the majority of students started premarital sex at age of $16-20$ years $208(83.9 \%)$ with mean age of $18.23 \pm 1.955$ years and age was not predictor of premarital sexual practice. This is different from study conducted in Harar revealed age is the strongest predictor of premarital sexual practice and the highest proportion, $48.1 \%$ of males and $37.8 \%$ of females, had their first sexual encounter at 15-17 years of age. The mean age at first sexual exposure among unmarried youths was 17.2 years (16.9 and 18 years for males and females respectively) [25].

Students who earn pocket money less than 400 birr were less likely to practice premarital sex than those who earn more than 1000 birr month $[$ AOR $=0.096,95 \%$ CI $=0.010,0.888]$. This in line with study done in Ethiopia showed that Income is the other common factor for premarital practice. Respondents who had pocket money were more likely to have pre-marital sexual practice than those who had not $[\mathrm{AOR}=2.2,95 \% \mathrm{CI}(1.14,4.05)][31]$. Improved socio-economic standards and nutrition have brought about changes in the physical aspect of adolescence; the age of onset of sexual maturation has been decreasing; growth and physical development are proceeding at an accelerated step [10]. This could be explained by other risk factors which are more accessible to economy class students like alcohol use, exposure to technologies which could increase the students' exposure to different films and Medias that are predictors of premarital sexual practice.

This study showed that having reproductive health information is protective against premarital sexual practice $[$ AOR $=0.995,95 \%$
$\mathrm{CI}=0.988,1.012]$. This is in line with existing literatures document that adolescents engage in premarital sex with insufficient knowledge of reproductive health and family planning, and the small proportion use contraceptive, especially condom [27]. Respondents who communicate a lot about love with their families were less likely to report pre-marital sexual practice than those who never communicate it with their families (AOR $=0.29,95 \%$ CI $[0.1,0.85])$ [31]. This could be explained by the fact that knowing risks for premarital sexual practice like HIV/AIDs and pregnancy could have changed participant's behavior to abstain from premarital sexual practice.

This study pointed out that participants who had exposure to erotic/ pornographic films were 3.84 times more likely [AOR = $3.854,95 \%$ CI $=0.945,11.055]$ to practice premarital sex than those who do not have exposure to it. This is similar with study done in Alamatatown; adolescents who watch sex/pornographic movies were more likely to engage in premarital sexual practice than those who don't. Another study showed that watching pornographic materials at age less than 18 years old was found to be associated with sexual initiation [27]. Similarly Study done in Asian country about premarital sexual intercourse among adolescents showed that, pornography viewing was found to be significant factor for premarital sex among boys [28]. This could be because adolescents who watch pornographic movies may develop unrealistic attitudes about sex, which leads them to engage insexual practice [16].

In this study $193(33.6 \%)$ of participants reported that they had alcohol use experience during study period and about 129 (66.8\%) of these students had sexual intercourse after taking alcohol and chat use $103(17.9 \%)$ of participants had chat chewing experience and among chewers $74(71.18 \%)$ had sex after chewing chat. This study revealed that abstinence from alcohol use $[\mathrm{AOR}=$ 
Table 3. Frequency Distribution of Social and Family Related Factors among AMU Students, March 2015.

\begin{tabular}{|c|c|c|}
\hline Number of sexual partners $(n=248)$ & Frequency & Percent \\
\hline One & 66 & 26.6 \\
\hline Two & 136 & 54.8 \\
\hline Above two & 46 & 18.5 \\
\hline \multicolumn{3}{|l|}{ Exposure to reproductive health information $(\mathrm{n}=575)$} \\
\hline Yes & 484 & 84.2 \\
\hline No & 91 & 15.8 \\
\hline \multicolumn{3}{|l|}{ Source of reproductive health information $(n=484)$} \\
\hline Radio and television & 186 & 38.4 \\
\hline Health institution & 110 & 22.7 \\
\hline School & 100 & 20.7 \\
\hline Newspapers, posters and leaflets & 82 & 16.9 \\
\hline Religious leaders & 5 & 1.0 \\
\hline Partner and other family members & 2 & 0.4 \\
\hline Boy/girl friend & 1 & 0.2 \\
\hline \multicolumn{3}{|l|}{ Discussion in family about sex related issues $(n=575)$} \\
\hline Yes & 190 & 33.0 \\
\hline No & 385 & 67.0 \\
\hline \multicolumn{3}{|l|}{ Frequency of discussion $(\mathrm{n}=190)$} \\
\hline Usually & 14 & 7.4 \\
\hline Occasionally & 100 & 52.6 \\
\hline Rarely & 76 & 40.0 \\
\hline \multicolumn{3}{|l|}{ Freedom of discussion $(\mathrm{n}=190)$} \\
\hline Very easy & 36 & 18.9 \\
\hline Easy & 74 & 38.9 \\
\hline Difficult & 44 & 23.2 \\
\hline Very difficult & 36 & 18.9 \\
\hline \multicolumn{3}{|l|}{ Attendance of religious services $(\mathrm{n}=575)$} \\
\hline Yes & 468 & 81.4 \\
\hline No & 107 & 18.6 \\
\hline \multicolumn{3}{|l|}{ Frequency of attendance $(n=468)$} \\
\hline Everyday & 207 & 44.2 \\
\hline At least once in a week & 209 & 44.7 \\
\hline At least once in a month & 37 & 7.9 \\
\hline At least once in a year & 15 & 3.2 \\
\hline Belief about pre-marital sexual practice $(\mathrm{n}=575)$ & & \\
\hline it is right & 157 & 27.3 \\
\hline it is wrong & 418 & 72.7 \\
\hline
\end{tabular}

Figure 4. Reason for Wrong Belief Towards Pre-marital Sexual Practice among AMU Students, March 2015 (n = 418 ).

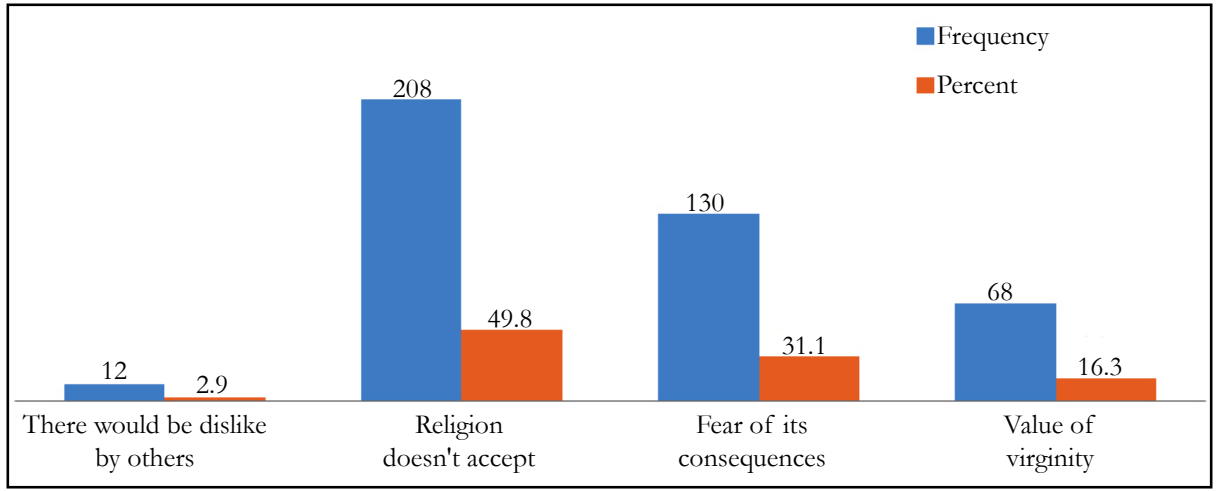

$0.300,95 \% \mathrm{CI}=0.198,0.454]$ and chat chewing $[\mathrm{AOR}=0.325$, $95 \% \mathrm{CI}=0.539,1.605]$ were protective against premarital sexual practice. This is consistent with study conducted in Jimma town respondents who are ever chewing khat were more likely to initiate premarital sex earlier $[\mathrm{AOR}(95 \% \mathrm{CI})=9.8(3.5,27.6)]$. The possible explanation for this association could be due to loss of track of mind induced by khat chewing which motivated them to have casual and early sexual initiation. In this study, alcohol users were more likely to begin premarital sexual intercourse earlier than those who didn't use alcohol [30].
This study also revealed that participants attending religious practice are less likely $[\mathrm{AOR}=0.403,95 \% \mathrm{CI}=1.555,1.626]$ to have premarital sexual practice unlike those not attending. This is similar with the findings from study conducted in Jimma university preparatory school showed that the desire to maintain relationship with friends of elders, living with single parents or poor religious activity are important in term of influencing adolescents sexuality [15]. 
Table 4. Multivariable Logistic Regression of Factors Predicting the Likelihood of Pre-marital Sexual Practice among Undergraduate Arba Minch University Students, Southern Ethiopia, May 2015, (n = 575).

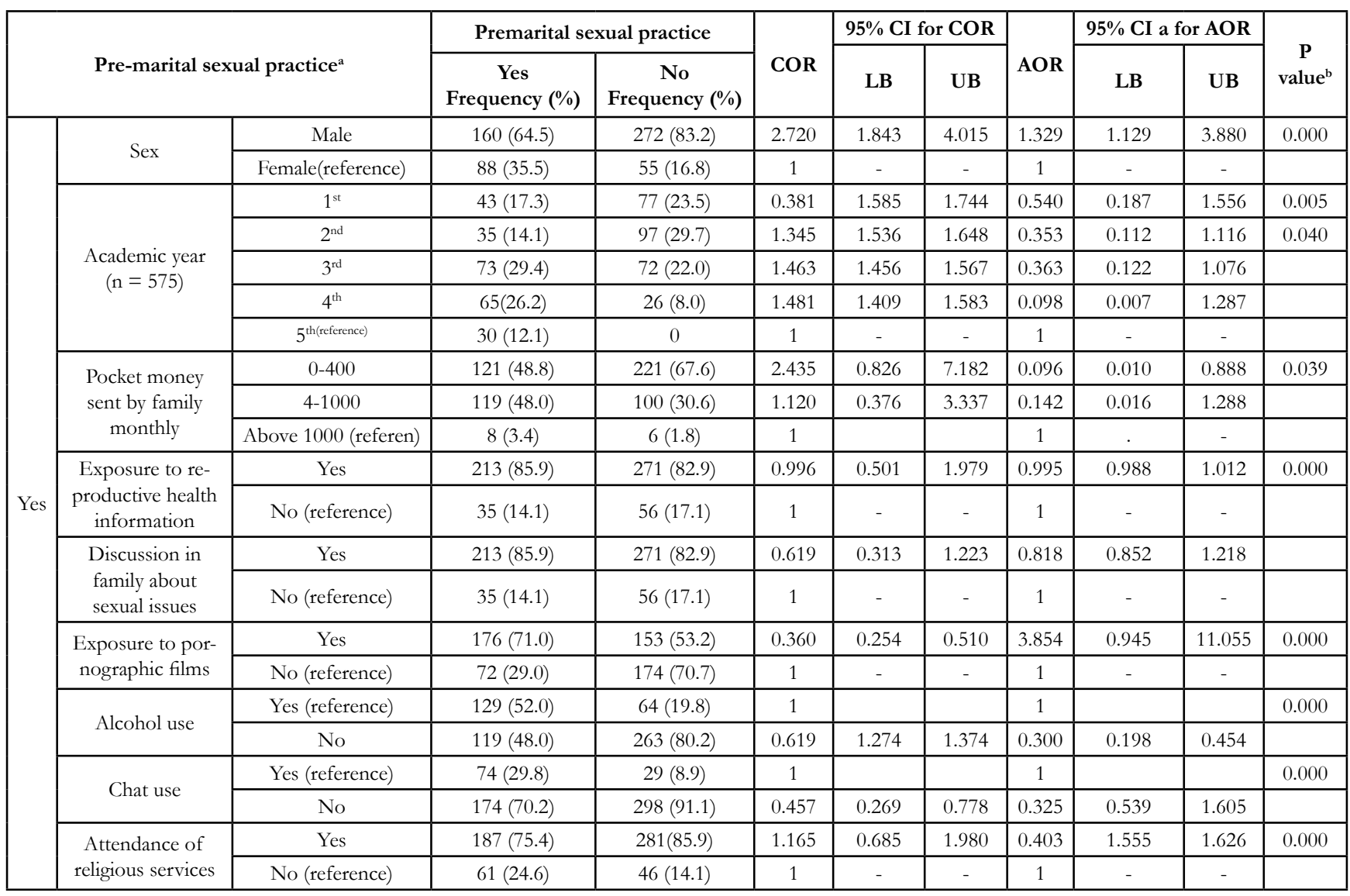

a 95\% Confidence Interval for the mean of Pre-marital sex experience; b P-value between groups significant at the 0.05 level.

\section{Strength and Weakness of the Study}

\section{Strength of the Study}

- The data was collected using a self-administered pre-tested questionnaire

- Adequate sample size was applied according to single population proportion formula

- Data collators were trained health professional

- Data quality is controlled throughout the study

- Double checking during data entry

\section{Weakness of the Study}

During this study there may be desirability bias.

\section{Conclusion and Recommendations}

\section{Conclusion}

More than one third of participants had premarital sexual practice and it is higher in males than females. Factors affecting premarital sexual practice include; Male sex, Academic year, Pocket money, Exposure to Reproductive health information, Family discussion about sexual issues, Exposure to pornographic films, Alcohol use, Chat chewing and attending religious services. The majority of respondents had information on sexuality and repro- ductive health mainly from (radio and television, health institutions, school and newspapers, posters and leaflets). There is attitude, knowledge and practice disparity; most of participants had exposure to reproductive health information and negative attitude against premarital sexual practice yet many of them practiced it.

\section{Recommendations}

Based on the findings of this study the following Recommendations are made and forward to: health sector, families, government and researchers as follows.

1. The fact majority of respondents were between the ages of 16-20 years points towards youths particularly students in high school level; so interventions focusing on this age group such as such as sex education focusing on behavior and practice.

2. Participants from good family standard engaged in premarital sexual practice than those from poor families. This calls for families to focus important things during developing child such as restricting access to advanced technologies, games and films to their age only. Since adolescents are for physically mature but while they are mentally not fit to choose the best from alternatives available at their hand.

3. Factors that initiate sexual activities such as Pornographic or erotic movies and other entertainment needs due attention from government and responsible bodies. 
4. Since the study revealed that disparity between knowledge, attitude and premarital sexual practice this, calls for future studies that are strong enough to determine causality of premarital sexual practice to peak out the real deterrent and iron shell behind premarital sex practices on university students in Ethiopia.

\section{References}

[1]. ZeraiKassaye Z (2005) Sexual experience and their correlates among JU students Jimma Ethiopia. Heal Sci. 15(1): 1-17.

[2]. Zelalem Fekadu (2001) Casual sex -debuts among female students in Addis Ababa, Ethiopia, J health Dev. 15(2): 109-116.

[3]. Fikadu A, FikaduK (2000) Creating a better future for Ethiopian youth. A conference on $\mathrm{A}$ and $\mathrm{H}$. THE O and vid and (Luel) packord foundation. Bahir dar, Ethiopia.

[4]. Ethiopia Demographic and Health Survey/EDHS 2011.

[5]. Tilahun M, Ayale G (2013) Factors associated with age at first sexual initiation among youths in Gamo Gofa, South West Ethiopia: a cross sectional study. BMC Public Health. 13: 622.

[6]. Deribew A (2009) Distribution of most at risk population group and their perception towards HIV/AIDS: a baseline survey in amhara region for the implementation of mobile HIV counseling and testing. Bethesda, MD: Private Sector Program-Ethiopia, Abt Associates Inc.

[7]. Hong Y, Li L, Yongyi B, Xunyu X, Shiyue L, et al., (2010) Family and peer influences on sexual behavior among female college students in Wuhan. Chin Women Health. 50(8): 767-782.

[8]. Habte D (2008) Assessment of the Distribution of At-risk Populations and HIV/AIDS Referral Services in Ethiopia: Baseline Assessment for Mobile HIV Counseling and Testing Program in Oromia Region. Bethesda, MD: Private Sector Program-Ethiopia, Abt Associates Inc.

[9]. Adamu R, Samuel M, Ingidashet S (2004) Patterns and correlates of sexual initiation, sexual risk behaviors, and condom use among secondary school students. Ethiop Med J. 10(1): 16-20.

[10]. Frehiwot Berhane, Yemane Berhane, Mesganaw Fantahun (2005) Adolescents' health service utilization pattern and preferences: Consultation for reproductive health problems and mental stress are less likely. Ethiop J Health Dev. 19(1): 29-36.

[11]. Hughas J, MC Cavley AP (1998) Improving the fit: Adolescents' needs and future programs for sexual and reproductive Health in developing countries, studies in family planning. 29(2): 233-245.

[12]. Asefaw (2003) Survey of sexual behavior of the students in relation to HIV/ AIDS in Harar town, Eastern Ethiopia.

[13]. Mitikie G, Tesfaye M, Ayele R, Gadisa T, Enqusillasie F, et al., (2005) HIV/ AIDS behavioral surveillance survey (BSS) Round two. Ethiopia.

[14]. Getachew MK, Emebet B, Nurilign AM (2014) Prevalence of Premarital Sexual Practice and Associated Factors among Alamata High School and Preparatory School Adolescents, Northern Ethiopia. Global J Medical res. 14(3)
[15]. Taye A, Asmare I (2016) Prevalence of Premarital Sexual Practice and Associated Factors among Adolescents of Jimma Preparatory School Oromia Region, South West Ethiopia. J Nurs Care. 5: 332.

[16]. Teka T, Azwihangwisi Helen Mavhandu-Mudzusi (2016) The prevalence of risky sexual behaviours amongst undergraduate students in Jigjiga University, Ethiopia. Health SA Gesondheid. 21(1): 179-186.

[17]. Seme A, Wirtu D (2008) Premarital sexual practice among school adolescents in Nekemte Town, East Wollega. Ethiopia J Health Deve. 22(2): 167173.

[18]. Mulu Tilahun Yigzaw, Alemayehu Worku Yalew, Alemayehu Bogale Mesfin (2014) AgumasieSemahegnDemisie. Sexual Initiation and Factors Associated with it among Addis Ababa University Undergraduate Students, Addis Ababa, Ethiopia. Am J Health Res. 2(5) : 260-270.

[19]. Cherie A, Berhane $Y$ (2012) Oral and anal sex practices among high school youth in Addis Ababa, Ethiopia. BMC Public Health. 12(5): 1-9.

[20]. World Health Organization (2006) Sexual behavior in context: A global perspective. Geneva: WHO Publication.

[21]. Oljira L, Berhane Y, Worku A (2012) Pre-marital sexual debut and its associated factors among in-school adolescents in Eastern Ethiopia. BMC Public Health.

[22]. Diarsvitri W, Utomo I, Neeman T, Oktavian A (2011) Beyond sexual desire and curiosity: sexuality among senior high school students in Papua and West Papua Provinces (Indonesia) and implications for HIV prevention. Cult Health Sex. 13(9): 1047-1060.

[23]. Fekadu M, Alemayehu W (2009) Age at sexual initiationand factors associated with it among youths inNorth East Ethiopia. Ethiop. J Health Dev. 23(2): 154-62.

[24]. Mee-Lian W, Roy K, David K, Hiok-Hee T, FongSeng L, et al., (2009) Premarital Sexual Intercourse among Adolescents in an Asian Country: Multilevel Ecological Factors. Pediatrics. 124(1): 44-52.

[25]. Korra A, Haile M (1999) Sexual behavior and level of awareness on reproductive health among youths : Evidence from Harar . Ethiopian J Health Dev. 13(2): 107-113.

[26]. Asrat A (2009) Assessment of sexual risk behaviors of in-school youth: effect of living arrangement of students, West Gojam zone, Amhara regional state. Ethiopia: Addis Ababa University.

[27]. Epha, Arh (2003) Task forcé Adolescent Reproductive Health Global and National initiatives: Lesson Learned.

[28]. Qiaoqin Ma (2006) Sexual behavior and awareness of Chinese university students in transition with implie drisk of sexually transmitted diseases and HIV infection: A cross-sectional study. BMC public Health. 6: 232.

[29]. Romel Saulog L (1997) Correlates of sexual Abstinence among Urban University Students in the Philippines. Intl Family PlanPersp. 23(4): 168-172.

[30]. Girma A, Fasil T, Abiot G (2016) Premarital Sexual Practice and Associated Factors among Preparatory School Students in Jimma Town, Oromia Region, South West Ethiopia. Journal of Biology, Agricul Healthcare. 6(15).

[31]. Hurissa BF, Tebeje B, Megersa H (2014) Prevalence of Pre-marital Sexual Practices and Associated Factors among Jimma Teacher Training College Students in Jimma Town, South West Shoa Zone, Oromiya Region, Ethiopia-2013. J Women's Health Care. 4: 221. 